\title{
Modelling and Simulation Support of EMS Processes
}

\author{
Jan Ministr \\ VSB - Technical University Ostrava, Faculty of Economics, \\ Sokolská 33, 701 21, Ostrava, Czech Republic \\ jan.ministr@vsb.cz
}

\begin{abstract}
In Environmental Management System (EMS) area there are inherently included received decisions which entail a great risk. Reducing this risk can be achieved by using dynamic simulation models of EMS processes, such as emergency plans. The dynamic model of problem area within the EMS allows predicting sufficiently the actual results of the proposed decision and supports creativity management. This paper describes the possibilities of modelling tools Witness in modelling and simulation of the EMS processes.
\end{abstract}

Keywords: EMS, Environmental Management System, Model, Process Modelling, Process Owner, Simulation.

\section{Introduction}

The Environmental Management System (EMS) processes belong usually to "hard" processes that require a very fast response time. The modelling and simulation tools of these processes represent the important support of decision making in the area of EMS. The usage of these tools increases the quality of decisions and optimizes the costs incurred to realize a decision [2]. The basic premise of this approach is the implementation of process management in the organization and creative approach of the process owners who are responsible for the effective progress of the processes [1].

Computer simulation of the EMS processes in the form of dynamic models represents a robust technique that allows solving many complicated problems in this area. There are two basic approaches to design changes in the EMS processes without using of simulation. The first approach uses the experience of managers and experts and to implement their proposed process modifications. However, this approach does not always improve the process because it is experience-based only. The second approach gradually try running some variant of the EMS process changes in practice and then choose the most suitable solution. The disadvantage of this approach lies in the need of implementing each alternative of process in practice, increasing cost and time requirements [6].

If the process owner wants to avoid the above problems the solution for optimizing EMS processes is to use dynamic simulation required process. First, there is a need to create a simulation model of the process and then choose the best fit solution based on experiments with the simulation model [9], [10] using the dynamic simulation. Simulation is also an important tool in the design of new, previously non-existent 
processes, which allows verifying the behaviour of proposed processes and thus avoiding errors at the design stage of the process [4]. The entire simulation process is shown in Figure 1. The great advantage of this method of decision making is the possibility of visualization both the running of processes and their monitored indicators.

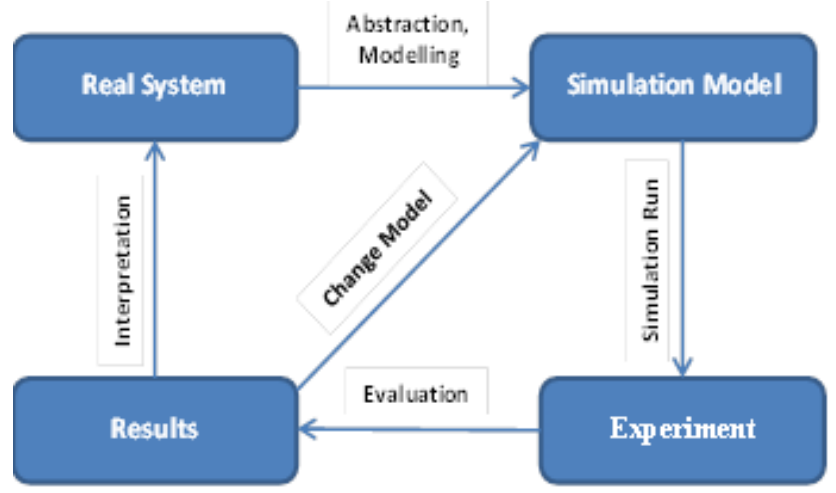

Fig. 1. Process of dynamic simulation (Source: [6])

\section{Process Modelling Support by Witness Software}

There are many tools for process modelling in practice but only a few are suitable for EMS dynamic process modelling. There are presented author's results based on own experience with modelling of EMS processes in the FirstStep, ARIS and Witness environment. The tool Witness appears to be the most appropriate for its universal properties.

The British software Witness Software from company Lanner Group Ltd. is intended to simulate the discrete event systems. The version "Manufacturing Performance Edition" is primarily used in practice which has the advantage of wide applicability in the simulation of logistics, production and service systems. Using of this version of Witness tool provides next possibilities for creation of EMS dynamic process models and simulation [5]:

- Risk reduction in decision making (accurately predicting how proposed changes to a facility or process will work).

- Proposing the optimal solution to decision makers (enables scenarios to be compared and the best option for the EMS to be graphically reported).

- Generating an operational asset (simulations deployed as robust applications become an asset in operational decision making).

- Supporting of investment decisions (provides evidence to identify profitable ideas and avoid costly mistakes). 


\subsection{Witness Developing Structure of Software}

The structure of Witness developing environment consists of three basic modules which enable the efficient creation of simulation models of the EMS processes as it is shown in Figure 2:

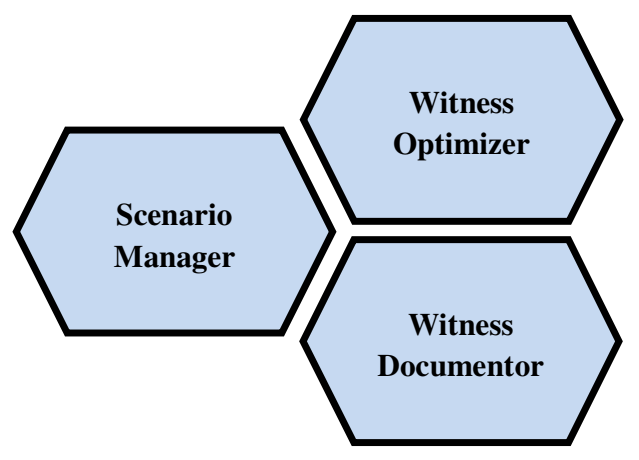

Fig. 2. Structure of witness modules (Source: own)

- Scenario Manager that offers a highly flexible framework for experimentation and analysis including visual interactive simulation which allows:

- Graphical creation of simulation model.

- Dynamic display of the simulated EMS process model.

- User interaction with the running model (the simulation halt, requirement input information from user).

- Witness Optimizer finds the best solutions for simulation model by the use of the latest sophisticated mathematical techniques and offers an easy-to-use interface and the presentation of optimal results in a selection of useful and innovative tables and graphs.

- Witness Documentor allows creation of a simple formatted version of the information included in a WITNESS model.

\subsection{Basic Building Blogs of Simulation Model of EMS Processes}

The Witness tool provides standard modelling elements which can be used to create a simulation model of the EMS process. These elements are grouped according to their properties into the following groups:

- Discrete elements which are main for economic and administrative processes modelling (Entities, Queues, Activities, Resources).

- Physical Handling Elements (Conveyors, Paths, Tracks, Vehicles).

- Power \& free elements which allow modelling the specialized form of transport systems (Network, Section, Station and Carrier).

- Continuous processing elements which are used to simulate models where continuous flow is a factor (Fluids, Processors, Tanks and Pipes). 
- Logical Elements and Modules which represent the data and reporting aspects of the model (Attributes, Variables, Files, Distributions, Functions, Part Files, Shifts and Modules).

- Graphical \& Reporting Elements (Pie Charts, Time series, Histograms and Reports.)

- Manipulating Elements (Rules, Expressions and Actions).

Created models of simulation can be stored in various formats which are shortly described in table 1 .

Table 1. Storage formats of Witness simulation models (Source: own)

\begin{tabular}{|c|l|}
\hline Format & Characteristic \\
\hline .MOD & $\begin{array}{l}\text { Standard model save format. It includes all the definition of the model } \\
\text { in a fast loading format. }\end{array}$ \\
\hline SIM & $\begin{array}{l}\text { Model and status file that saves the model at a particular point in a } \\
\text { model run. When this file is loaded again it is possible to view run sta- } \\
\text { tistics and even to run the model on from that saved point in time. }\end{array}$ \\
\hline .LST & $\begin{array}{l}\text { Library file. This is a text definition of a model file. It provides a way } \\
\text { of looking at a model file in a standard editor such as Notepad or } \\
\text { Wordpad. }\end{array}$ \\
\hline DES & $\begin{array}{l}\text { A designer elements file. This file format saves a single tab of a set of } \\
\text { designer elements to a file. This provides easy portability of designer } \\
\text { elements between models. }\end{array}$ \\
\hline MDL & $\begin{array}{l}\text { A module file. This saves part of a model (or all if a single module) to a } \\
\text { file for re-use in another model. }\end{array}$ \\
\hline .WXM & A WITNESS model in XML format. \\
\hline
\end{tabular}

\subsection{The Process of Creating the Simulation Model of EMS Project}

The Witness GUI (Graphical User Interface) provides users an intuitive way to create a simulation model of the EMS process that can be divided into several phases as it is shown in Figure 3.

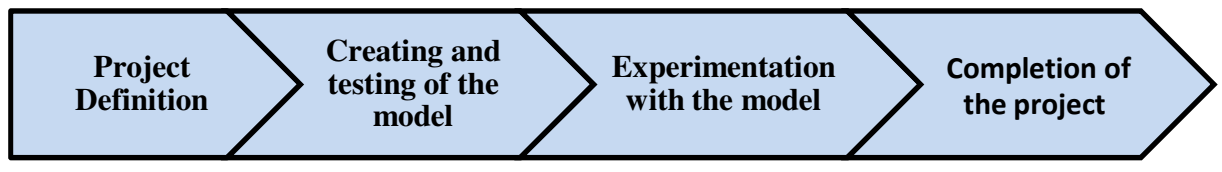

Fig. 3. The process phases of project simulation (Source: own)

The Project definition is the first phase of project simulation that consists of three steps which determine the success of the whole project, these steps are:

- Establishing objectives of the project of modelling and simulation of the EMS process. 
- Deciding the scope and the level of the detail in the simulation model. It is important to limit the scope of the model as far as possible. At the beginning of the model-building process, small additions to the model lead to large increases in its accuracy. However, as the model becomes more detailed each subsequent addition adds less to the model's accuracy. This is particularly true when you are trying to model human behaviour, which is often inconsistent [5]. The graph below shows a typical relationship between the model's level of detail and the model's accuracy.

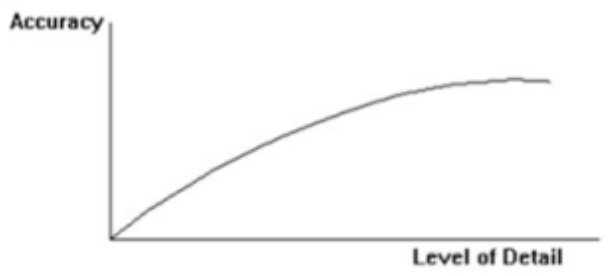

Fig. 4. Effect of adding detail to a simulation model (source: [5])

- Collecting data for creating the simulation model where elected information is likely to fall into one of three categories:

- Available - data is readily available and it is in an appropriate format that the model can use immediately.

- Not available but collectable - data is either in an incorrect format or it has not been collected before. You might need to perform a small work study in order to collect this type of data (for example, timing certain processes manually).

- Neither available nor collectable - data is not currently available and it is not easily collectable (for example, for a model of a new process of the EMS). If the data is neither available nor collectable you must use estimates. You can obtain useful estimates by:

o Using manufacturer's data - Machine or special tools often include information (for example, reliability data) in their promotional literature and machine specifications.

- Sensitivity analysis - involves replacing an unknown parameter (for example, a machine cycle time) with a high value and a low value in turn and comparing the results of the entire simulation.

The second phase of Creating and testing of the model consists of four steps:

- Structuring the simulation model identifies the most difficult areas for the simulation model building. It has usually a form of sketch of the situation to be modelled (inputs, outputs, key activities, etc.).

- Building the simulation model where elements of the simulation model are created (defining, displaying and detailing them), then linking the elements together with rules of its behaviour. In this step, more complex logic of the model is built by using actions of active elements. 
- Verification of the simulation model ensures that the content of the model is consistent with expectation of the process owner.

- Validation of the simulation model investigates the accuracy of the model compared with the real world.

Experimentation with the simulation model investigates the behaviour of the simulation model in a number of what-if scenarios. It is relatively alone phase of the project whose steps are the simulation runs. Successful experimentation involves using a warm-up period or starting conditions, deciding on a suitable run-length, and running the model with more than one random number stream.

Completion of the project is final phase of the simulation project that consists of next three steps:

- Generation of the reports and documentation of simulation where Witness offers standard types of reports (Time series, Histogram, Pie etc.). Documentation makes the simulation model easier to understand if it needs to examine the simulation model at a later date [7], [8]. The WITNESS Documentor module allows creating a report of the names, notes and other property fields within a model.

- Presentation of results depends on the size of the simulation project and the culture of user's organization [3]. An animated model provides an effective communication tool to support decision making [6].

- Implementation of model results depends on the developer's ability to convince the process owner that the project results should become the part of the decisionmaking process and that the model is not used to simply justify a past decision. Actions resulting from simulation project should be implemented in the real world.

\section{Application of Dynamic Simulation of EMS Process}

Witness environment has been used by the author for modelling the activities of Call Centre of Fire and Rescue Corps which coordinates the deployment of fire and rescue techniques. Created simulation model was a part of the research plan no. MSM0021622418 supported by the Czech Ministry of Education, Youth and Sports and the research project no. SP/4H4/168/07 supported by the Czech Ministry of Environment. The application of dynamic simulation in Witness environment pursued two main objectives:

- The first objective was optimization of the activities of Call Centre (respectively department of dispatching) and setting the optimal number of dispatchers.

- The second objective was creation of the data collection for optimization of the deployment of fire and rescue techniques in the terms of arrival time, increase of operational capability and efficiency of Fire and Rescue Corps in the monitored district. On a base of collected data, a number of what-if scenarios have been created and they were used to create the quality emergency plans. 


\subsection{Potential Benefits of Simulation in Witness Environment}

This created simulation model presents a detailed process model where each individual carried out activity of employees can be seen on the screen as shows the figure 5 . Each stage of the process is presented to show the input queue. The entities are processed and the employees (dispatchers) are used to perform the required tasks.

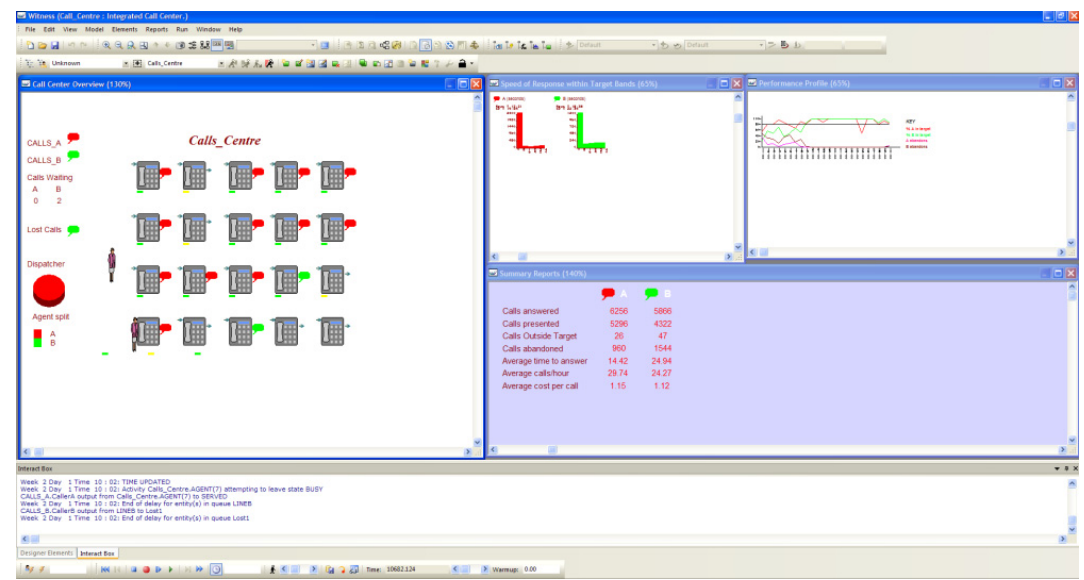

Fig. 5. The simulation model of Call Centre (source: own)

One of the important properties of the Witness environment is the possibility to quickly generate a view of the model using 3D graphics with a choice of the point of view on the model as shown in Figure 6. This property makes easier communication with the process owner who is responsible for its running and maintenance.

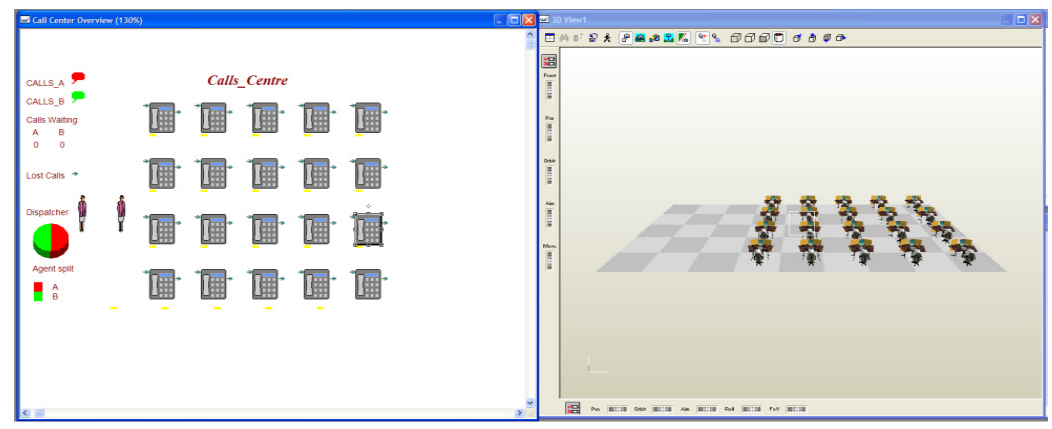

Fig. 6. Using the 3D presentation (source: own)

Next important facility is the possibility of using the Witness Optimizer which offers to user to search for the best answers in the wide range of possibilities and usually finds these within a small percentage of the possible number of simulation runs. Implemented changes of simulation results helped to achieve the objectives of the project as it is published in the report of project no. SP/4H4/168/07. 


\section{Conclusion}

Using the dynamic simulation models of the EMS processes provides useful possibilities of decision making for EMS process owners in critical situations, such as emergency plans.

Using of modelling tools, such as Witness, which were primarily designed to simulate production - logistics processes also appears to be very effective in the case of a dynamic simulation of the EMS processes. Simulation models of processes in both areas generally require a very short response time of the system. This fact opens the possibility of using simulation models and their simulation results for the partial test, the feasibility of emergency plans and behaviour of the EMS systems in crisis conditions on a wider scale.

In the case of an emergency, correct implementation of the simulation results can save considerable amount of economic resources and it can possibly save lives.

\section{References}

1. Becker, J., Algermissen, L., Falk, T.: Modernizing Processes in Public Administrations: Process Management in the Age of e-Government and New Public Management (BPM Competence). Springer, New York (2012)

2. Doucek, P.: Dynamic modelling of the software development process. Cybernetics and Systems 27(4), 403-410 (1996)

3. Doucek, P.: Human Resources in ITC - ITC Effect on GDP. In: IDIMT-2010: Information Technology - Human Values, Innovation and Economy 18th Interdisciplinary Information Management Talks. Book Series: Schriftenreihe Informatik, vol. 32, pp. 97-106. Trauner Verlag, Linz (2010)

4. Greasley, A.: Simulation Modelling for Business. Asgate, Burlington (2004)

5. Lanner Group. Witness - Service and proces performance Edition (2010)

6. Manlig, F.: Computer Simulation of Discrete Events. MM Industrial Spectrum 10, 34-35 (1999)

7. Ministr, J., et al.: The IT Service Continuity Management Principles Implementation by Method A2. In: IDIMT- 2009 Systems and Humans - A Complex Relationship - 17th Interdisciplinary Information Management Talks Proceedings. Schriftenreihe Informatik, vol. 29, pp. 131-139. Traunr Verlag, Linz (2009)

8. Ministr, J., Števko, M.: Human resources Requrements for Professional Management of ITSCM Processes. In: IDIMT-2010: Information Technology - Human Values, Innovation and Economy 18th Interdisciplinary Information Management Talks. Schriftenreihe Informatik, vol. 32, pp. 57-64. Trauner Verlag, Linz (2010)

9. Ráček, J., et al.: Integration of eGovernment Services of the Czech Ministry of Environment. In: 6th International Eastern Europe elGov Days: Result and Trends. Österreichische Computer Gesellshaft, Linz (2008)

10. Štefánik, M., Hřebíček, J., Ráček, J.: Interoperability in E-Government Services for Environment Protection. In: Eastern European e-Gov Days: Best Practice and Innovation, pp. 19-22. Austrian Computer Society, Wien (2007) 